\title{
Sustain City - A Cyberinfrastructure-Enabled Game System for Science and Engineering Design
}

\author{
Ying Tang \\ College of Engineering \\ Rowan University \\ 201 Mullica Hill Rd. \\ Glassboro, NJ 08028 \\ tang@rowan.edu
}

\author{
Sachin Shetty \\ College of Engineering \\ Tennessee State University \\ 3500 John A Merritt Blvd \\ Nashville, TN 37209 \\ sshetty@Tnstate.edu \\ John Henry \\ Education Information \\ Resource Center \\ 107 Gilbreth Parkway \\ Mullica Hill, NJ 08062 \\ jhenry@eirc.org
}

\author{
Talbot Bielefeldt \\ International Society for \\ Technology in Education \\ 180 West 8th Ave. \\ Eugene, OR 97401 \\ talbot@iste.org \\ S. Keith Hargrove \\ College of Engineering \\ Tennessee State University \\ 3500 John A Merritt Blvd \\ Nashville, TN 37209 \\ skhargrove@Tnstate.edu
}

\author{
Kauser Jahan \\ College of Engineering \\ Rowan University \\ 201 Mullica Hill Rd. \\ Glassboro, NJ 08028 \\ Jahan@rowan.edu
}

\begin{abstract}
The emergence of transformative technological advances in science and engineering practice has necessitated the integration of these advances in engineering classrooms. In this paper, we present the design and implementation of a virtual reality game system that infuses cyberinfrastructure (CI) learning experiences into the Project-Lead-The-Way (PLTW) pre-engineering classrooms to promote metacognition for science and engineering design in context. The CI features, metacognitive strategies, context-oriented approaches as well as their seamless integration in the game system are elaborated in detail through two game modules, Power Ville and Stability. Both games involve students in the process of decision-making that contributes to different aspects of city infrastructures (energy and transportation). The evaluation of Power Ville deployment in a PLTW classroom is also presented. The preliminary assessment confirms the usability of CI and metacognitive tools in science and engineering design.
\end{abstract}

\section{Categories and Subject Descriptors}

\section{I.3.7 [Three Dimensional Graphics and Realism]}

\section{General Terms}

Design, Human Factors, Experimentation, and Verification

\section{Keywords}

Virtual Reality Game, Metacognition, Science and Engineering Design

\section{INTRODUCTION}

Political, social and economic advances in the United States during the $21^{\text {st }}$ century will be possible only if the intellectual potential of American's youth is developed now. However, a

Permission to make digital or hard copies of all or part of this work for personal or classroom use is granted without fee provided that copies are not made or distributed for profit or commercial advantage and that copies bear this notice and the full citation on the first page. To copy otherwise, or republish, to post on servers or to redistribute to lists, requires prior specific permission and/or a fee. Copyright CJOCSE, a supported publication of the Shodor Education Foundation Inc. number of recent reports make it clear that the United States is losing ground on key indicators of innovation and progress because of its poor performance in teaching math and science [3, 19]. Pre-college education, in particular, is lagging well behind its mandate to educate all children to higher standards, especially in areas that prepare students for science, technology, engineering, and mathematics (STEM). This eliminates many of the best and brightest schoolchildren from the ranks of future scientists and engineers. Many students who do undertake science and engineering studies in college are unprepared and drop out in frustration, while other potentially capable students never consider these subjects in the first place. Therefore, developing educational practices and settings in our K-12 classroom becomes extremely important; especially the ones that promote $21^{\text {st }}$ century skills and help learners build up their "habit of mind" [4] for scientific reasoning and inquiry.

The radical and transformative technological revolution has resulted in fundamentally new ways of science and engineering practice. This paradigm shift has a significant impact on the skills needed for a diverse science and engineering workforce that is capable of designing and deploying cyber-based systems, tools and services. However, engineering and science education has not kept pace with this evolution, especially at the K-12 level. There is a growing need to incorporate cyberinfrastructure (CI) learning experiences into classrooms of secondary education. Two key CIbased technologies which have tremendous impact on education and training are 1) networked computing technologies; and 2) virtual learning environments, including games, simulations and modeling. Networked computing technologies enable new forms of collaborative learning to meet different learner's requirements. Virtual games allow interactions within immersive digital worlds that promote learning through authentic and engaging play. Simulations and models help provide insights into scientific phenomenon making difficult abstract concepts and large data sets accessible in ways that are more visual, interactive, and concrete. As such, infusing virtual reality (VR) games with simulations and models into a classroom setting becomes essential.

Living through the hurricane Katrina and its aftermath and reflecting on these experiences from the technical and humanist standpoints has led us realize the importance of bringing the perspectives of humanities and social sciences into design education [9]. Although some institutions have taken steps to meet 
this need, most of those efforts have focused on either a capstone design sequence [11], undergraduate research experience [5], or developing a full-fledged degree program [16]. Research indicates that such design education should start earlier for prospective and beginning science and engineering students, encouraging them to optimize their design activities not only in technical aspects, but also in social and environmental areas [18].

Motivated by these general remarks, this project, as collaboration between Rowan University and Tennessee State University (TSU), developed and implements a VR game system, called "Sustain City", which is closely tied to the Project-Lead-The-Way (PLTW) curriculum [22] and provides CI learning experiences to pre-engineering students. In particular, our design carefully balances engagement and learning with the following unique aspects: (a) visual modeling and simulation tools in the games provide insights into scientific concepts and phenomena, and help analyze data in a more visual and interactive way; (b) the networked educational environment transcends the boundaries of school-based education to leverage learning taking place anytime and anywhere, and promotes learning through collaboration; (c) metacognitive strategies and problem-based learning advance learners' strategic thinking and enhance their social, methodological and professional competence for a broader perspective on design; and (d) each game module is self-contained with a focus on particular fundamental science and engineering concepts, so it can be used as stand-alone contributions to a typical science, technology-based, or pre-engineering course or used in a coordinated manner through the PLTW curriculum. In these games, students are central and important participants of a virtual world in which they can become environmental scientists, bridge construction engineers, and traffic engineers. They learn how to investigate, design and pose solutions that have an impact on the world. More importantly, students often find a passion for curricular content while navigating through the games and begin to see themselves as problem solvers. Such engagement allows students to better appreciate the content's value.

The focus of this paper is to illustrate the design and developmental aspects of our approach through an example of two VR games, Power Ville and Stability. Our assessment of the games when deployed in a high school classroom provides insights into effectiveness of the games in providing CI learning experiences. The rest of the paper is organized as follows. Section 2 gives the project overview with an emphasis on the integrated approach and three metacognitive interventions used in the design of the VR game. Section 3 provides the design and implementation of Power Ville and Stability. Section 4 outlines the evaluation results and findings from the assessment of the Power Ville game, followed by the conclusions in Section 5.

\section{PROJECT OVERVIEW}

\subsection{Integrated Approach}

Recent reports have indicated that many STEM classes rely heavily on textbooks but are weak on examples, such that students are exposed to encyclopedias of fact without ever engaging in the science and engineering process [6]. The perceived dullness or complexity of the material, a lack of concrete applications, and individual preconceptions further make introductory science and engineering classes difficult for students, leading to lower recruiting and retention rates of science/engineering majors. Thus, it is crucial to design a fun learning environment that engages students in the exploration of real science and engineering applications and promotes strategic, constructive, and big-picture thinking and problem solving. As for the "big-picture" strategy, Bordogna [1] has well expressed the need for curricular integration as, "Most curricula require students to learn in unconnected pieces - separate courses whose relationship to each other and to the engineering process are not explained until late in a baccalaureate education, if ever. ... The content of the courses may be valuable, but this view of engineering education appears to ignore the need for connections and for integrationwhich should be at the core of an engineering education."

In our VR game system design, integration refers to a series of VR games in a given context (like "Sustain City") that individually have a focus on particular fundamental science and engineering concepts, can be used as a replacement of traditional laboratory settings of courses at different levels of the PLTW curriculum, and eventually proceed to an increasingly complex open-ended capstone project at the senior level of the curriculum. Such integration enables students to understand that their courses are part of a flow that contributes to the design of a system rather than being separate bodies of knowledge. This idea is clearly presented in Fig. 1 with the explanation below.

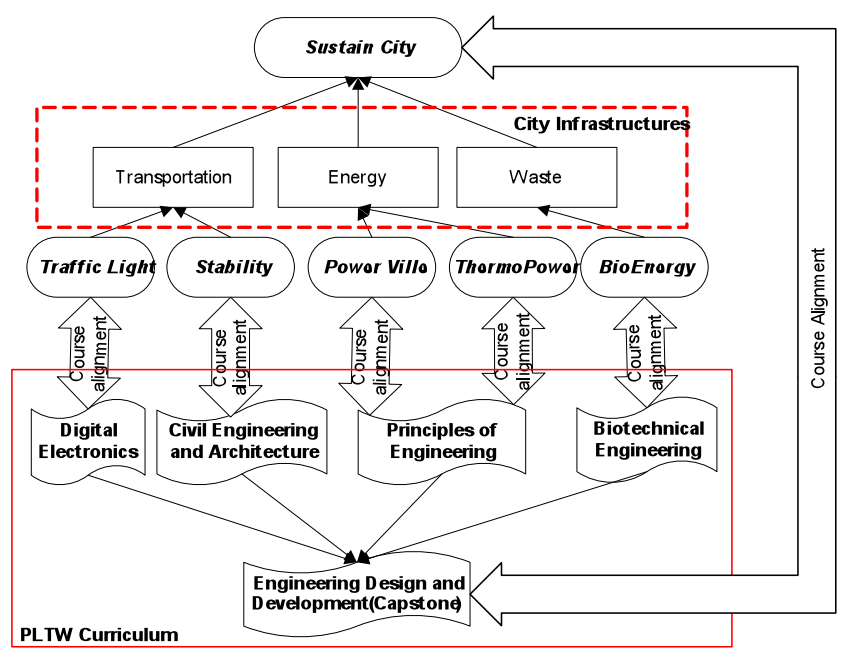

Fig. 1: The curriculum alignment and integration

A sustainable city is a city designed to improve the quality of life, including ecological, cultural, political, institutional, social, and economic components without leaving a burden on the future generations [23]. It is also an exquisite combination of interacting systems (infrastructures) that can be designed and analyzed using multidisciplinary engineering and scientific principles. With the future sustainable city as a broader context and the city infrastructures as the themes, Sustain City consists of a series of VR games (e.g., Power Ville, Traffic Light, and Stability, etc.) that provide students an opportunity to learn what it means to be a scientist, engineer, or mathematician who helps design and maintain an eco-city. This opportunity also brings their content knowledge and skills learned in the traditional classroom environment to a contextual reality. As shown in Figs. 1 and 2 (the screenshots from Sustain City for different game theme environments), our games align with the curriculum and academic subject matter - including math, circuit design, or persuasive writing - and each game taps into subject knowledge. The eventual integration of individual game components will be performed by teams of students in the senior-level capstone course, resulting in a fully-functional virtual eco-city. Through demonstration, explanation, and practice in different aspects of 
Sustain City, students are motivated to see the interconnection between their courses as a progression of increasing design complexity.

\subsection{Metacognitive Interventions}

The process of learning is a very complex cognitive task that requires a lot of effort and motivation from learners. Research indicates that the more students are aware of their learning process, the more they can control such matters as goals, dispositions, and attention, and the better they become successful learners. Such awareness and monitoring processes are often referred to as metacognition -" the processes in which the individual carefully considers thoughts in problem solving situations through the strategies of self-planning, self-monitoring, self-regulating, self-questioning, self-reflecting, and or selfreviewing" [7]. In light of this, it benefits education to not only create an interesting and stimulating learning environment for students (i.e., VR games), but also to naturally integrate important learning tools (i.e., metacognitive interventions) into the interactive game activities.
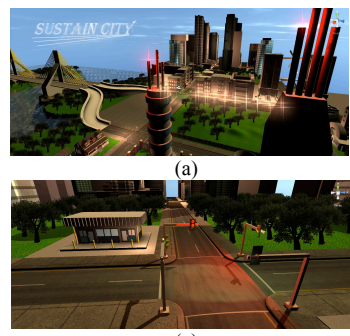

(c)

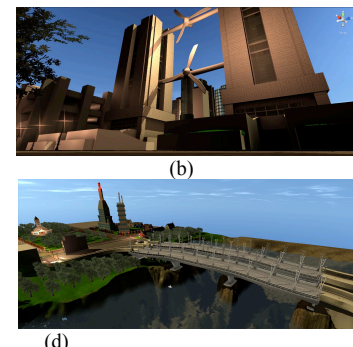

Fig. 2: Screenshots from Sustain City: (a) Overview of Sustain City; (b) Power Ville; (c) Traffic Lights; (d) Stability

- Learning Road Map - Learning roadmap provides study guides that endow students with the capability to find relevant information and to capture key concepts in the study materials [13]. Depending on game content, road map in our game might be a task list that guides students to navigate through game assignments and retrieve important information (Fig. 3); or it might be a set of suggestions designed to lead students through a problem solving process by directing attention to key ideas and suggesting the application of proper skills (Fig. 4).

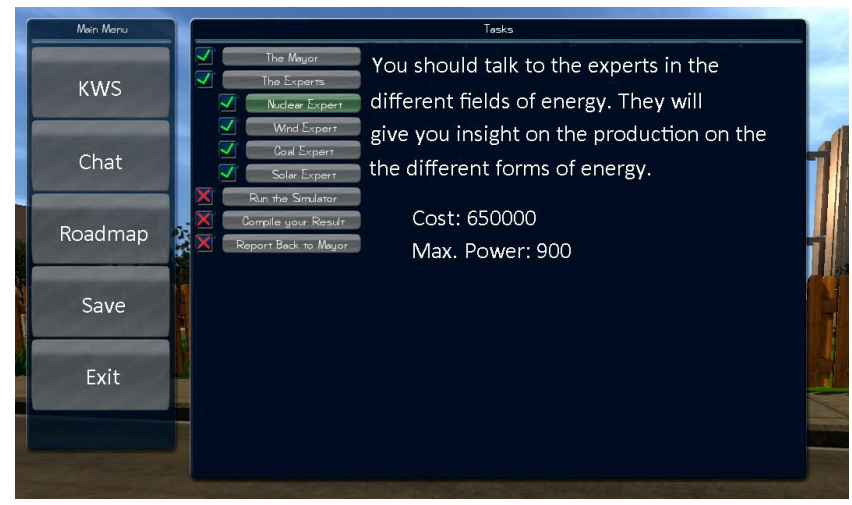

Fig.3: The roadmap in Power Ville game

- What I Know-What I Want to Know- What I have Solved (KWS) training - KWS is adapted from a well known reading strategy, What I Know-What I Want to Know- What I Have Learned (KWL) [12]. It typically provides a threecolumn chart structure to activate students' prior knowledge by recalling what students know about a problem $(\mathrm{K})$, to motivate students to read/think by asking what they want to know (W), and finally to review what part of the problem has been resolved and what is yet to be solved (S). This type of intervention is usually implemented in the traditional classroom environment with facilitation from instructors. However, in a virtual game environment, students are often left alone with the responsibility to explore and to figure out problems themselves. The lack of guidance makes it difficult to implement such an intervention because not all students are motivated to use it without facilitation. The solution we devised uses a series of progressive prompts at key game stages, as exemplified in Fig. 5 (a). The information provided by students at different prompts is automatically recorded into the corresponding portions of their KWS chart (Fig. 5 (b)). More importantly, the What-I-Know portion of the KWS chart will be used to compose the player's final report, which will deliver to the city Mayor and ultimately to his or her instructor for grading. Therefore, the player might need to modify his or her KWS as often as needed, since his or her knowledge progresses with the game (this part will be elaborated in detail in the next section).

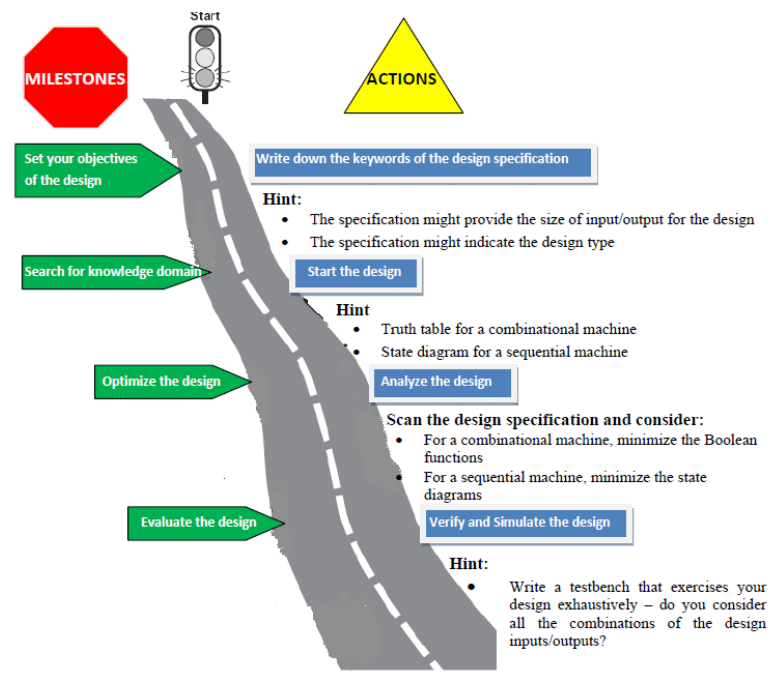

Fig. 4: A sample road map for a traffic light design

- $\quad$ Think-Aloud-Share-Solve (TA2S) training - As Vygotsky pointed out, learning is an inherently social and cultural rather than individual phenomenon [17]. The interactions among peers allow intellectual synergy of many minds to bear on a problem, and promote the social stimulation of mutual engagement in a common endeavor. TA2S, implemented in our game system through online chatting, is a variation of the collaborative learning strategies, ThinkAloud [8] and Pair Problem-solving [10].

\subsection{Cyberinfrastructure Tools}

According to the National Science Foundation, CI describes an environment in which computing systems, data storage systems, advanced instruments and data repositories, visualization environments, and people are all linked together by software and high performance networks to improve scholarly productivity and to enable breakthroughs not o possible. Although SustainCity has much in common with the GreenCity [20] and the Mobility [21], our design explores way beyond the scope of these commercial games with seamless integration of key elements of cyber infrastructure, namely collaboration and communication in a 
visualization environment. For example, in Power Ville, students are hired by the city Mayor to analyze viable energy sources for the future of the city. An interactive simulator as shown in Fig. 6 is designed in the game to help students visually view environmental and economic impacts of four available energy options (coal, nuclear, solar and wind) for the city. In some other games, such as Stability, students are introduced to a 3D bridge model (Fig. 2 (d)), where they can visually analyze the structure impact of gravity and other loading effects on the bridge visually, and provide mitigation solutions to reinforce the bridge structure. To complete this task, students need to apply their structural systems fundamentals, including forces, loads, beams, and columns, to vary model parameters, and to derive their correlations to bridge performance. We view games like these as environments that make curricular content a necessary tool and that position the learner as a leader who transforms a virtual world

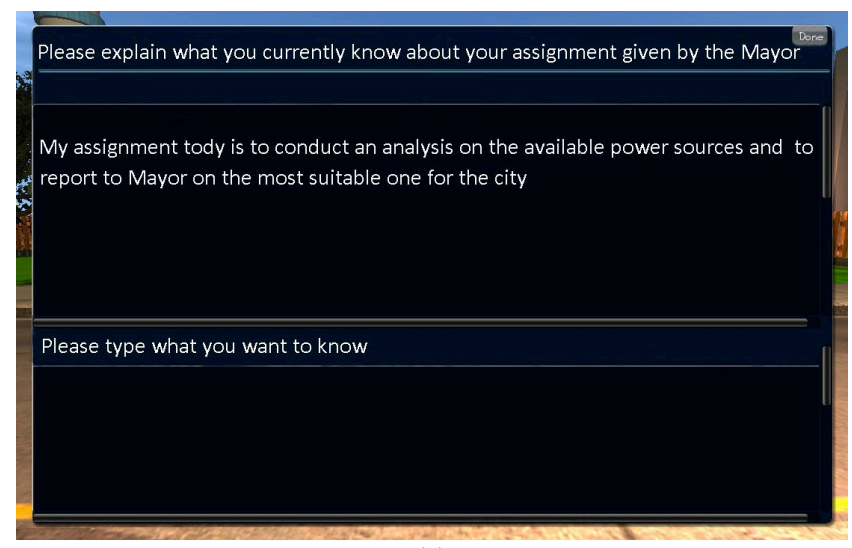

(a)

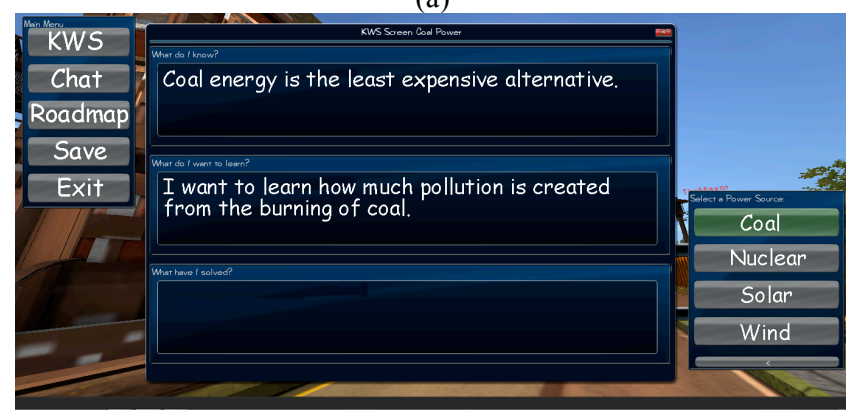

(b)

Fig. 5: (a) a prompt after a player visited the coal building; (b) the student's inputs to the prompt is recorded in his or her KWS

To enable the network functionalities that allow students to share ideas and knowledge with their on-line group members, our design uses a client/server architecture. Only the instructor has access to the server program, where he or she can set up the group size and group password (Fig. 7 (a)). At the client site, all games are a group assignment that requires each student in a group to log into the system with a security password. While logged in, the players can participate in group discussions (Fig. 7(b)) on the problem/solutions through a synchronous chat function. Group members are not necessarily present at the same place and time. The discussions as well as each player's actions are recorded in the system. The data is only accessible to instructors and researchers, providing a resource to analyze student performance and game effectiveness in promoting learning.

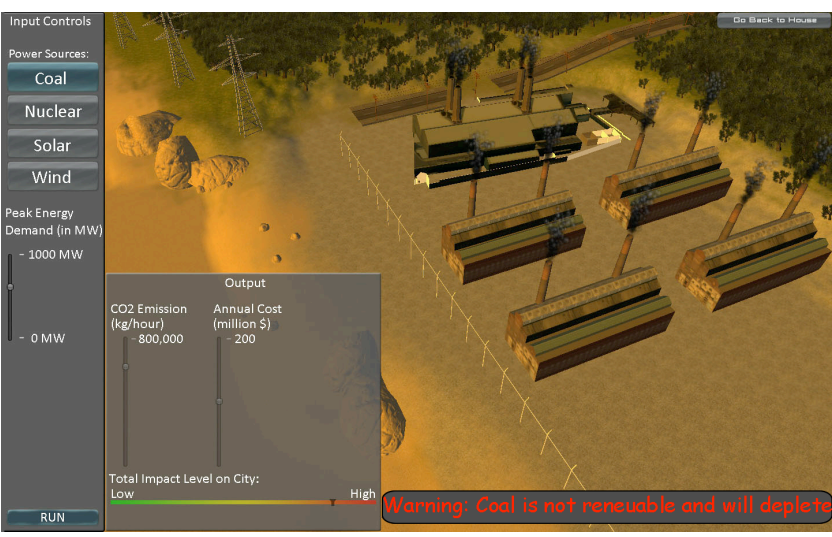

Fig. 6: The interactive simulator in Power Ville

\section{Sample Game Theme and Design}

In this section, we describe the educational gaming process in two modules, Power Ville and Stability. These modules exemplify the seamless integration of fun, metacognitive interventions and engineering problem-solving in a well-balanced engagement and learning process.

\subsection{Power Ville}

Cooking a dinner, heating a house, lighting a street, and running a factory - all of these need power. Energy is thus at the heart of everybody's quality of life. How to generate and use energy that satisfies increasing energy needs while combating climate changes at the same time becomes an unprecedented challenge for a sustainable city development. Bringing such real science and engineering design problem as well as involved societal and environmental issues into the Principles of Engineering course is the core of this game.

The goal of the Power Ville VR game is to educate students about four energy choices (coal, wind, solar, and nuclear) and the impact of those choices on the environment of the city. To implement this goal, the game incorporated the CI tools, which are gaming, simulation and networking, and the three metacognitive interventions.

\section{Establishing a Meaningful Role}

Goal identification is of importance in game playing to motivate players and promote a deep understanding of content [15]. In Power Ville, each player is introduced to the game by visiting the city hall and talking to the Mayor of the city. The conversation asks the player to take the task, as a consulting engineer, to conduct and report a thorough analysis on the most suitable form of energy for the future of the city with the given city budget and energy demands. Meanwhile, the player is urged to visit different facility buildings and talk to individual power system experts for vital information regarding the pros and cons of various energy sources. Succeeding in this role requires that the player understand and apply the knowledge about power and energy systems learned in both the classroom and the game environment, together with the writing skills to collect appropriate evidence and compose a persuasive piece of writing. In fact, the game is designed in the way that automatically composes a final report for the player by using every justification the player provides in the question prompts at different game stages. 

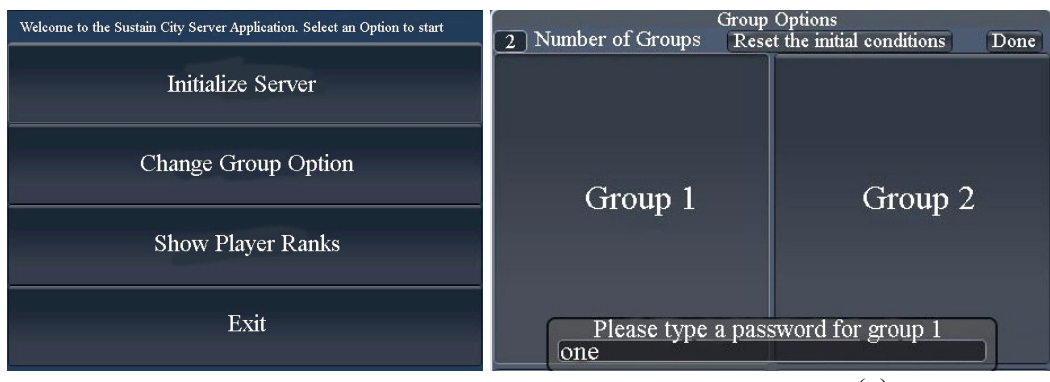

(a)
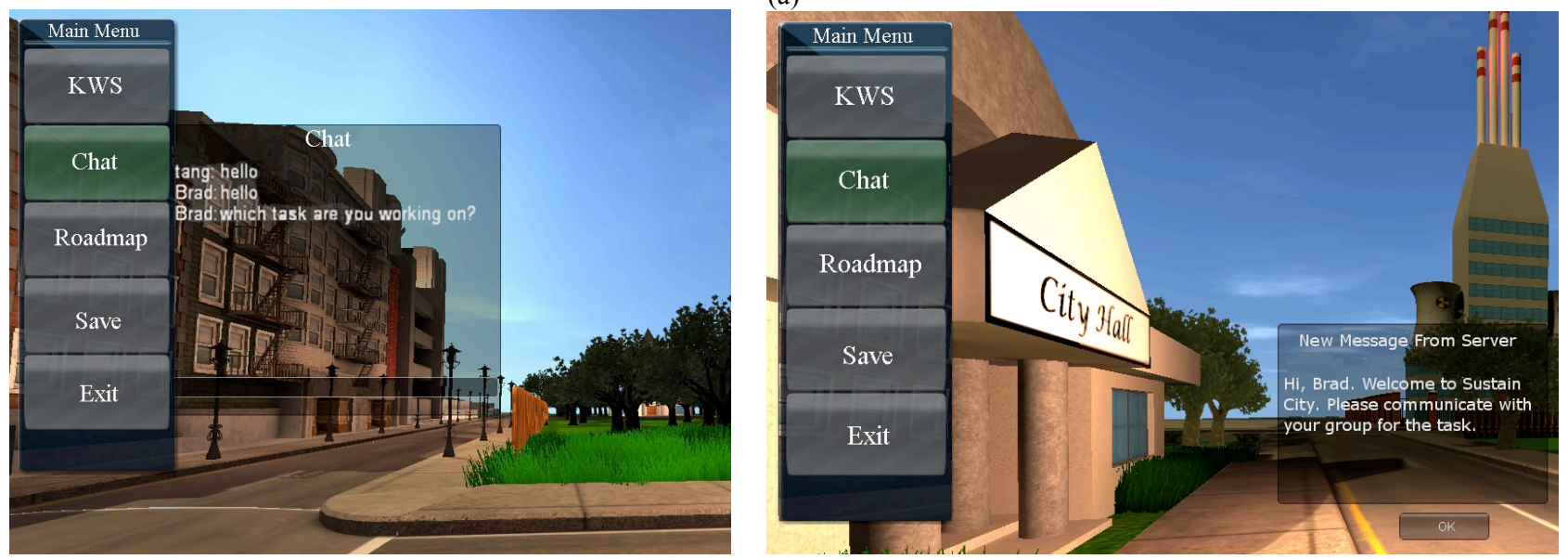

(b)

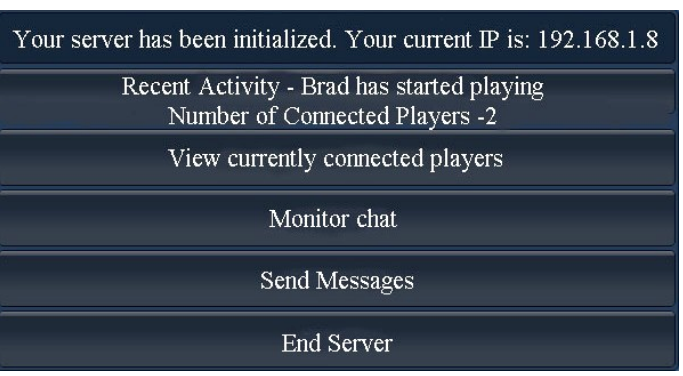

cent Activity - Brad has started playing

Number of Connected Players -2

View currently connected players

Monitor chat

Fig. 7: The networking activities at both (a) the server side and (b) the client side

\section{Exploring CI Tools for a Better Solution}

After players exit the city hall, they must talk to different power system experts located in offices spread across the city. The game environment is designed for easy navigation as each office building has identifiable and unique landmarks. For instance, the solar-power building contains racks of solar-panels and the wind power building has large turbines that tower over the streets below. In addition, the Road Map tool is always available on a game menu for players to retrieve the next task in the must-do list and to show the cost and the peak energy output of a particular power source. The game menu is launched through the TAB key. After players interact with individual experts, watch a video, and do a quiz, or play a mini-game on the energy production process they are exploring, they are prompted to write about stories from characters they talk to. These notes are recorded in KWS. Players can launch KWS via the game menu to modify their notes. As the logs for each player, particularly the What-I-Know section of the KWS, are automatically used to compose his or her final report, the player has to craft the notes using the most compelling support for their argument. Soon after visiting all experts and making their way to their apartment, players are provided with two other $\mathrm{Cl}$ tools, Simulator and Optimization Programming, to help formulate their answers as to the best energy source for the future of the city. The Simulator allows players to select each of four different power sources with a given demand as well as other source-dependent constraints, such as sun exposure for solar power and wind speed for wind power. It then visually outputs the total amount of $\mathrm{CO}_{2}$ emissions and the total environmental impact of the chosen power source. As shown in Fig. 6, the simulation run of the coal power source indicates the footprint of the power generation and warns the player the potential of coal being depleted as a non-renewable energy.

\section{Discovering Consequences of different decision-makings}

Computing has made possible profound leaps of innovations and imagination. This paradigm shift has a significant impact on the skills needed for a diverse science and engineering workforce who can bring the power of computing-supported problem-solving to an expanded field of endeavors. Power Ville provides students the ability to apply computational thinking through the use of the Optimization Programming tool. This tool takes inputs from a player (i.e., the data he or she collects through the game as for the cost and peak energy production of a particular power, and the city budget and energy demands), and his or her preliminary decision to rank four power sources based on their environmental impact. The choice each player makes at this point affects the final outcome of the optimization, ultimately determining his or her argument as for the best energy source. This decision is eventually brought to an in-game evaluator that uses a preprogrammed scoring method to assess the quality the decision. Fig. 8 shows two possible outcomes. When a player ranks coal as the power source with the least environmental impact, his or her preliminary understanding was criticized by Optimization Programming tool as a one-star decision (see Fig. 8 (a)). On the other hand, the correct understanding of the environmental impact of the four power sources was rated as a four-star decision (See Fig. 8 (b))

\subsection{Stability}

There is a strong interrelationship between success and failure in engineering. When engineers properly anticipate the possible failure modes of a structure or system, they can obviate them by design [14]. Stability actually explores such nature of design success through failure, providing students a virtual environment to reinforce the structure of a bridge to help prolong its lifetime. This game project fits nicely to the core of the "Civil Engineering 
and Architecture" course into the PLTW curriculum. Introducing a vision of engineers tackling real life problems to impact the quality of life generates tremendous enthusiasm and attracts more students, especially underrepresented groups, into engineering.
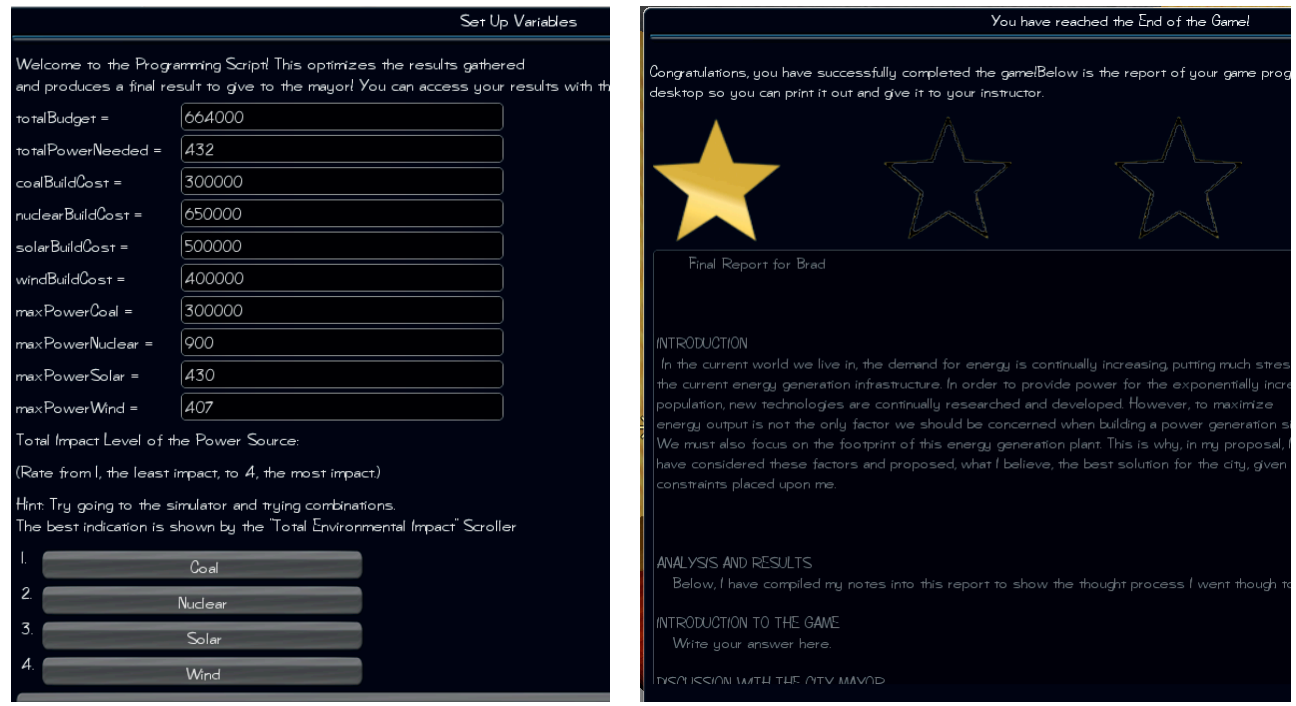

(a)

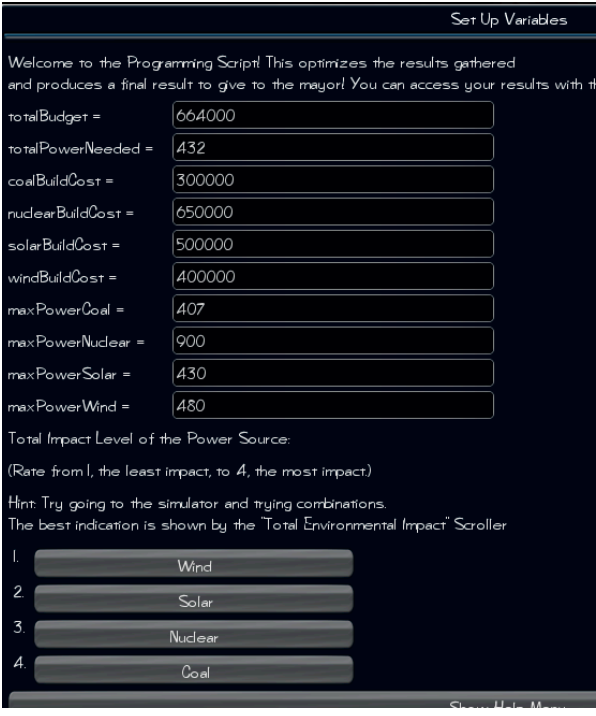

In the introductory scene of Stability, where a busy bridge appears against the backdrop of the city, players are invited to conduct a what-if stability analysis of the bridge with the intention of estimating its life-time. To complete this task, players have to navigate back and forth between two game scenes multiple times to make different observations and to collect the best evidence in justifying their findings. First is the input scene, where players must provide the mechanical and structural specifications of the bridge (e.g., the length and width of the bridge), average amount of traffic per day (e.g., the number of cars per day), and climate situation (e.g., snow). The inputs each player provides at this point affect the kinds of bridges that the player interacts with, analyzes and draws a conclusion about.

Next comes with the analysis and mitigation scene. With the specifications being provided by the player, a simulator allows the player to analyze and visualize the bridge deflection (Fig. 9). Such experiential practice of visualizing bridge performance with changing loads, sizes and climate situations greatly helps players to draw correlations between bridge dimension, traffic, environment, and deflection. In addition, the analysis retrieves crucial facts, such as the amount of force and moments exerted on the bridge, and the area of beams required at the center and ends. The latter information is of significant importance in determining the number of beams and spacing required to mitigate bridge bending. Instead of recommending a solution, the game provides students a look-up table as shown in Table 1, where the cell values represent the required area of beams, and the column and row values correspond to the number and spacing of beams. There is no one-to-one correspondence between the value calculated from the analysis and the ones available in the table. Students must try different options that are close to the calculated value, observe individual reduction effects, and make an optimal decision for the best alleviation option. The game brings academic content, such as live loads, dead loads, beams and columns, into a contextual reality. Students not only hone their structural system 
design skills, but also find an appreciation for their content knowledge as well as the excitement of seeing themselves as problem solvers.

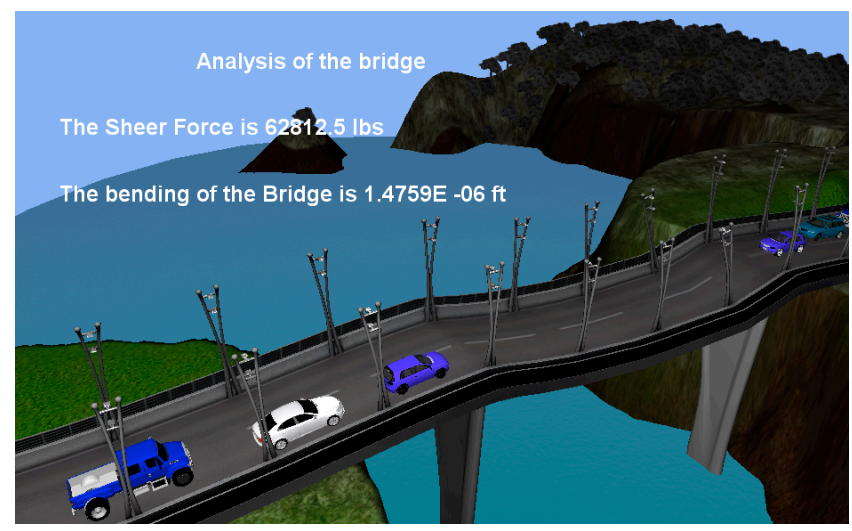

Fig. 9: The analysis scene of Stability

Table 1: Lookup table to identify number and spacing of beams

\begin{tabular}{|c|c|c|c|c|c|c|c|c|c|}
\hline & \multicolumn{9}{|c|}{ Number } \\
\hline SPACING & 3 & 4 & 5 & 6 & 7 & 8 & 9 & 10 & 11 \\
\hline 3 & 0.44 & 0.78 & 1.23 & 1.77 & 2.40 & 3.14 & 4.00 & 5.06 & 6.25 \\
\hline 3.5 & 0.38 & 0.67 & 1.05 & 1.51 & 2.06 & 2.69 & 3.43 & 4.34 & 5.36 \\
\hline 4 & 0.33 & 0.59 & 0.92 & 1.32 & 1.80 & 2.36 & 3.00 & 3.80 & 4.68 \\
\hline 4.5 & 0.29 & 0.52 & 0.82 & 1.18 & 1.60 & 2.09 & 2.67 & 3.37 & 4.17 \\
\hline 5 & 0.26 & 0.47 & 0.74 & 1.06 & 1.44 & 1.88 & 2.40 & 3.04 & 3.75 \\
\hline 5.5 & 0.24 & 0.43 & 0.67 & 0.96 & 1.31 & 1.71 & 2.18 & 2.76 & 3.41 \\
\hline 6 & 0.22 & 0.39 & 0.61 & 0.88 & 1.20 & 1.57 & 2.00 & 2.53 & 3.12 \\
\hline 6.5 & 0.20 & 0.36 & 0.57 & 0.82 & 1.11 & 1.45 & 1.85 & 2.34 & 2.89 \\
\hline 7 & 0.19 & 0.34 & 0.53 & 0.76 & 1.03 & 1.35 & 1.71 & 2.17 & 2.68 \\
\hline 7.5 & 0.18 & 0.31 & 0.49 & 0.71 & 0.96 & 1.26 & 1.60 & 2.02 & 2.50 \\
\hline 8 & 0.17 & 0.29 & 0.46 & 0.66 & 0.90 & 1.18 & 1.50 & 1.89 & 2.34 \\
\hline 9 & 0.15 & 0.26 & 0.41 & 0.59 & 0.80 & 1.05 & 1.33 & 1.69 & 2.08 \\
\hline 10 & 0.13 & 0.24 & 0.37 & 0.53 & 0.72 & 0.94 & 1.20 & 1.52 & 1.87 \\
\hline 11 & 0.12 & 0.22 & 0.34 & 0.48 & 0.65 & 0.86 & 1.09 & 1.39 & 1.70 \\
\hline 12 & 0.11 & 0.20 & 0.31 & 0.44 & 0.60 & 0.78 & 1.00 & 1.27 & 1.56 \\
\hline 13 & 0.10 & 0.18 & 0.29 & 0.41 & 0.55 & 0.73 & 0.92 & 1.17 & 1.44 \\
\hline 14 & 0.09 & 0.17 & 0.27 & 0.38 & 0.51 & 0.68 & 0.86 & 1.09 & 1.34 \\
\hline 15 & 0.09 & 0.16 & 0.25 & 0.35 & 0.48 & 0.63 & 0.80 & 1.02 & 1.25 \\
\hline 16 & 0.08 & 0.15 & 0.23 & 0.33 & 0.45 & 0.59 & 0.75 & 0.95 & 1.17 \\
\hline 17 & 0.08 & 0.14 & 0.22 & 0.31 & 0.42 & 0.56 & 0.71 & 0.90 & 1.10 \\
\hline 18 & 0.07 & 0.13 & 0.21 & 0.29 & 0.40 & 0.53 & 0.67 & 0.85 & 1.04 \\
\hline
\end{tabular}

\section{PRELIMINARY ASSESSMENT AND LESSON LEARNED}

In fall 2011, Power Ville was piloted in Principles of Engineering (POE) course at Burlington County Institute of Technology - a vocational school in New Jersey. One focus of POE is types of energy (non-renewable and renewable) and energy distribution. After learning these concepts in lectures, the class of 15 students played Power Ville as part of their laboratory activities. An online survey, administrated by the International Society for Technology in Education (ISTE), was then given to the students upon their completion of the game. The survey instrument, as provided in
Appendix, is particularly designed to assess the game's realism, the utility and usability of the metacognitive and CI tools, and students' impressions of what they had learned. It is important to note that this was formative data collection from students who are essentially beta testers. It is valid for suggesting game improvements, but not valid for making generalizations about any larger population.

One of the important findings from the survey is that some additional scaffolding may be necessary for students to get the most benefit from the game experience. For instance, the metacognitive tools were generally usable for students without much assistance, but the students reacted differently to Road Map, KWS, and chat. Road Map was the most popular. About half the students used KWS, but were not sure of its value. One student commented, "I felt like the KWS was a bit unnecessary; however, if you were to create a notebook to take notes during the videos I believe that it would be used." In fact, the note-taking function is present; but the student did not find it. Similarly, few students used chat (although, possibly because of personal computing experience, most predicted they would use it for future problemsolving). One student felt that KWS was "redundant if you have chat," as if the KWS structure of questions and the ability to ask questions were interchangeable. A larger issue is to help students understand that KWS is a simplified, specific instance of a general problem-solving framework that they will need to use throughout their careers in addressing novel challenges.

Minor interface adjustments might make KWS and chat more accessible and integrated, or the instructors might need to do some modeling of collaborative problem solving. For example, chat is currently designed to be launched through onscreen menu. A "You Got a Message" type of note will pop up on the top right corner of the game GUI whenever a group member initiates chat with the player. The current design raised a lot of suggestions from the students during their play as how to "tweak" the interface to improve its accessibility. For instance, a scrolling chat box at the bottom of the screen would be much better than going through hierarchical menu options.

The popularity of Road Map as a resource compared to KWS may be related to students having more experience with linear labs and projects, and thus being more familiar with this type of guidance. The students reported little experience with either tool prior to playing Power Ville. The larger question is how Power Ville and future games might be crafted to increase the emphasis on openended problem solving and the need to use appropriate tools for that purpose.

In terms of CI tools, videos and simulations were considered valuable by most students. Their impact on student learning was also partially reflected in student responses to other open-ended questions. For instance, students were able to provide important justifications when prompted to discuss energy sources with an advocate of a particular approach, such as "You have to factor in the cost, the power it supplies, and the effectiveness over $X$ amount of years." "The best way to select an energy source is to focus on being environmentally friendly first. Then find the most cost effective that will produce enough energy for your needs." Students also commented on the most important things they learned through the game such as "The most important thing that I learned was to be environmentally friendly rather than being the most cost and energy efficient", and "How money can decide on what energy source you can have to run your city". Although about a third of the stuldents had prior programming experience, the programming in the game was deemed hard, and was the tool 
most likely to require teacher assistance. Given that programming is to play a larger role in subsequent games, we plan to design additional instructions and/or internal resources to support use of this tool.

Overall, there was considerable variation in responses to most questions, indicating that the items were appropriate in addressing a range of student backgrounds and attitudes. Some felt the game was too elementary, others found it enlightening about aspects of energy generation. All but one student felt that the game was more realistic than textbook problems, although no students felt it was truly like an authentic job assignment. When asked how, after playing the game, they might discuss power options with an advocate for one or another energy source, students came away with a variety of opinions. A third of the students emphasized that "it depends" on balancing a variety of factors. Another third had pro-environmental or pro-energy-production positions. Others had more nuanced points of view, such as the need to have more than one energy source, or the need to find out what the people affected value most

Future evaluation will involve interviews of students in addition to surveys. It will be important to know more about what specific features of the experience elicit their responses. For example, are students who find the game "elementary" responding to the engineering facts (which are covered by instructors prior to the game experience) or to the problem-solving context?

Student responses were mostly articulate and to the point, and some students seemed to have a career focus. One commented, "Online chat is absolutely necessary in anything that involves engineering. Teamwork is very important and I use it so my fellow students and I can learn from each other or work together." In general, however, the student responses were focused on the game context. It was not clear from the survey the extent to which students recognized that the game represented authentic professional activities: meetings with clients, preparation of complex project maps, formal brainstorming to identify knows and unknowns, collaboration with colleagues, and delivery of reports based on findings.

\section{CONCLUSION}

This paper addresses the inclusion of CI-learning experiences into the PLTW curriculum. In particular, the pedagogical approach develops a series of virtual reality games seamlessly integrated into different levels of the PLTW courses. The content and features of the games as well as their alignment with the curriculum are clearly presented through two interactive game examples, Power Ville and Stability. The preliminary assessment of Power Ville presents encouraging results as the students loved the game as an interactive and fun deliverable method of learning. The insights on how and why students responded to different tools provide a solid foundation to leverage our game system through iterative design-based research [2].

\section{ACKNOWLEDGMENTS}

This work is supported in part by the National Science Foundation grant \#OCI-1041306 and \#EEC-0935089. The authors would like to thank Aaron Johnson, Bradley Ebinger, and Christopher Franzwa for their helps in producing the screen shots presented in the work.

\section{REFERENCES}

[1] J. Bordogna, "Next generation Engineering: Innovation through integration," in Proc. NSF Eng. Educ. Innovator's Conf., April 8, 1998, Keynote address. http://www.nsf.gov/pubs/1998/nsf9892/next.htm

[2] Dede, C., "Why design-based research is both important and difficult," Educational Technology, 45, 1, pp. 5-8, 2005.

[3] Douglas, J., Iversen, E., and Kalyandurg, C., "Engineering in the K-12 Classroom - An Analysis of Current Practice and Guidelines for the Future," http://teachers.egfi-k12.org/wpcontent/uploads/2010/01/Engineering in the K-

12 Classroom.pdf.

[4] Duschl, R. A., and D. H. Gitomer, "Strategies and Challenges to changing the focus of assessment and instruction in science classrooms," Educational Assessment, 4:37-74, 1997.

[5] Harper, L. E., "The social consequences of design: PBL workshops for undergraduate researchers," Proceedings of American Society for Engineering Education Annual Conference, Session 3261, 2004.

[6] Herbert, B. E., "The role of scaffolding student metacognition in developing mental models of complex, Earth and environmental systems," DFG-NSF International Workshops on Research and Development in Mathematics and Science Education, Washington, D. C., Nov. 2003.

[7] Hyde, A. and Bizar, M. Thinking in context, White Plains, NY: Longman, 1989.

[8] Kim, B., Park, H., and Baek, Y., "Not just fun, but serious strategies: using meta-cognitive strategies in game-based learning," Computers \& Education, 52, 2009, pp. 800-810.

[9] Lima, M., "Engineering education in the wake of hurricane Katrina," Journal of Biological Engineering, 2007, 1:6.

[10] Narode, R. B., "Pair Problem-Solving and Metacognition in Remedial College Mathematics," Technical Report, http://www.eric.ed.gov/ERICDocs/data/ericdocs2sq1/content storage 01/0000019b/80/1c/53/3b.pdf.

[11] Neeley, K., Elzey, D., Bauer, D., and Marshall, P., "Engineering in context: a multidisciplinary team capstone design experience incorporating real world constraints," Proceedings of American Society for Engineering Education Annual Conference, Session 3461, 2004.

[12] Ogle, Donna M. (1992). KWL in action: Secondary teachers find applications that work. In E. k. Disher, T. W. Bean, J. E. Readence, \& D. W. Moore (Eds.), Reading in the content areas: Improving classroom instruction (3rd ed., pp. 270281). Dubuque, IA: Kendall-Hunt.

[13] Oliveira, M. and Serrano, J. A., "Learning roadmap studio: new approaches and strategies for efficient learning and training processes," http://www.elearningeuropa.info/files/media/media16938.pdf

[14] Petroski, H., Success through failure: the paradox of design, Princeton University Press, Feb. 2006.

[15] Sasha A. Barab, Melissa Gresalfi and Anna Arici, "Why Educators should care about games," Teaching for the $21^{\text {st }}$ Century, Vol. 67, No. 1, pp. 76-80

[16] Schumacher, J. and Gabriele, G. A., "Product design and innovation: a new curriculum combining the humanities and engineering," Proceedings of the $29^{\text {th }}$ ASEE/IEEE Frontiers in Education Conference, Session 11a6, San Juan, Puerto Rico, Nov. 10-13, 1999.

[17] Vygotsky, L. S. (1986). Thought and language. Cambridge, MA: MIT Press. 
[18] Yasuhara, K., Morozov, A., Kilgore, D., Atman, C., and Loucks-Jaret, C., "Considering life cycle during design: a longitudinal study of engineering undergraduates," Proceedings of American Society for Engineering Education Annual Conference, AC 2009-1728, 2009

[19] "Cyberinfrastructure for Education and Learning for the Future: A Vision and Research Agenda," Technical report, Computing Research Association. http://archive.cra.org/reports/cyberinfrastructure.pdf.

[20] Green http://ready2beat.com/entertainment/games/greencity-newversion-sim-city-games/linkout.

[21] Mobility game, http://www.mobilityonline.com/en/informations/generalinformation.html.

[22] Project-Lead-The-Way, www.pltw.org

[23] What is a sustainable city?" http://archive.rec.org/REC/Programs/SustainableCities/what.html.

\section{Appendix:}

\section{Power Ville Feedback Survey}

1. To what extent did this assignment in the game seem like a realistic engineering problem?

- Not Very. It was like any other textbook assignment.

- Somewhat. It was more realistic than working problems in a textbook.

- Very. It seemed like something I might do some day on a job.

2. Please rate the usability of the following game tools

\begin{tabular}{|l|l|l|l|l|l|}
\hline $\begin{array}{l}\text { Q2 response } \\
\text { options }\end{array}$ & $\begin{array}{l}\text { Unassisted } \\
\text { on 1st } \\
\text { attempt }\end{array}$ & $\begin{array}{l}\text { Unassisted } \\
\text { on 2-5 } \\
\text { attempts }\end{array}$ & $\begin{array}{l}\text { With } \\
\text { peer } \\
\text { help }\end{array}$ & $\begin{array}{l}\text { With } \\
\text { teacher's } \\
\text { help }\end{array}$ & $\begin{array}{l}\text { Did } \\
\text { not } \\
\text { use }\end{array}$ \\
\hline KWS & & & & & \\
\hline Road map & & & & & \\
\hline $\begin{array}{l}\text { Online chat } \\
\text { with your } \\
\text { group players }\end{array}$ & & & & & \\
\hline Simulator & & & & & \\
\hline $\begin{array}{l}\text { Programming } \\
\text { code }\end{array}$ & & & & & \\
\hline $\begin{array}{l}\text { Information } \\
\text { acquisition } \\
\text { tools }\end{array}$ & & & & & \\
\hline
\end{tabular}

3. In the game, you gathered information on power sources by talking to the Mayor and energy experts in the information acquisition stage. How often did you use the following tools during this stage?

4. In the game, you analyzed information for your final report in the analysis and decision making stage. How often did you use the following tools during this stage?
5. How helpful were the following tools for you to accomplish the assignment in the game?

\begin{tabular}{|l|l|l|l|}
\hline $\begin{array}{l}\text { Q5 response } \\
\text { options }\end{array}$ & $\begin{array}{l}\text { Not very. } \\
\text { They made } \\
\text { no } \\
\text { difference in } \\
\text { my game } \\
\text { progress. }\end{array}$ & $\begin{array}{l}\text { Somewhat. } \\
\text { They helped, } \\
\text { but I could } \\
\text { have } \\
\text { succeeded } \\
\text { without them. }\end{array}$ & $\begin{array}{l}\text { Very. They } \\
\text { really helped } \\
\text { me } \\
\text { understand } \\
\text { what I had to } \\
\text { do next. }\end{array}$ \\
\hline KWS & & & \\
\hline Road map & & & \\
\hline $\begin{array}{l}\text { Online chat with } \\
\text { your group } \\
\text { players }\end{array}$ & & & \\
\hline $\begin{array}{l}\text { Videos on } \\
\text { different energy } \\
\text { sources }\end{array}$ & & & \\
\hline Mini-quizzes & & & \\
\hline Simulator & & & \\
\hline $\begin{array}{l}\text { Programming } \\
\text { code }\end{array}$ & & & \\
\hline
\end{tabular}

6. If you could keep only one of these tools in the game, which one would you select?

7. If you could eliminate only one of these tools in the game, which one would you remove?

8. Before playing Power Ville, how often had you used each of these tools for solving problems in school work?

9. How likely are you to use these tools on your own in engineering or other subjects?

\begin{tabular}{|l|l|l|l|}
\hline Q8-9 response options & Never & $\begin{array}{l}\text { Once or } \\
\text { twice }\end{array}$ & +3 times \\
\hline KWS & & & \\
\hline Road map & & & \\
\hline $\begin{array}{l}\text { Online chat with your group } \\
\text { members }\end{array}$ & & & \\
\hline Simulator & & & \\
\hline Programming code & & & \\
\hline
\end{tabular}

10. You get in a discussion with a person who is totally for or against nuclear, solar, coal or wind energy. What would you tell them, as an engineering student, about the best way to select an energy source?

11. What is the most important thing you learned from playing Power Ville?

12. What is the most important thing you need to learn next for a clean power production system design?

\begin{tabular}{|l|l|l|l|l|}
\hline $\begin{array}{l}\text { Q3-4 response } \\
\text { options }\end{array}$ & $1-2$ times & $2-4$ times & $4+$ times & never \\
\hline KWS & & & & \\
\hline Roadmap & & & & \\
\hline Online Chat & & & & \\
\hline
\end{tabular}

